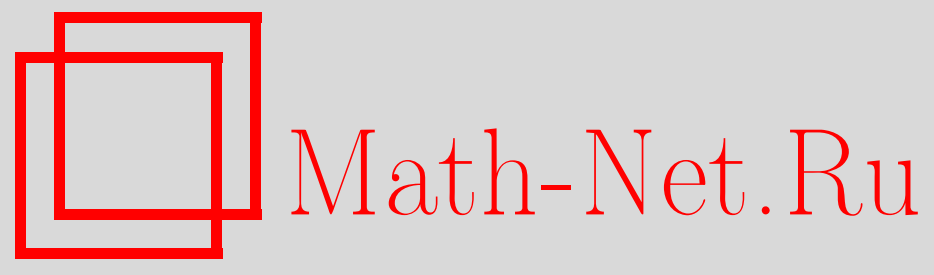

M. Kaminski, Central limit theorem for certain classes of dependent random variables, Теория вероятн. и ее примен., 2006, том 51, выпуск 2, 418-425

DOI: https://doi.org/10.4213/tvp65

Использование Общероссийского математического портала Math-Net.Ru подразумевает, что вы прочитали и согласны с пользовательским соглашением

http://www . mathnet.ru/rus/agreement

Параметры загрузки:

IP : 3.93 .64 .190

26 апреля 2023 г., 15:31:51 


\title{
REFERENCES
}

1. Arrow K. J. Essays in the Theory of Risk-bearing. Amsterdam: North-Holland, 1970.

2. Cheridito P., Summer C. Utility maximization under increasing risk aversion in oneperiod models. - Finance Stoch., 2006, v. 10, p. 147-158.

3. Delbaen F., Grandits P., Rheinländer T., Samperi D., Schweizer C., Stricker C. Exponential hedging and entropic penalties. - Math. Finance, 2002, v. 12, № 2, p. 99-123.

4. Harrison J.M., Pliska S.R. Martingales and stochastic integrals in the theory of continuous trading. - Stochastic Process. Appl., 1981, v. 11, № 3, p. 215-260.

5. Kramkov D. O. Optional decomposition of supermartingales and hedging contingent claims in incomplete security markets. - Probab. Theory Related Fields, 1996, v. 105, № 4, p. 459-479.

6. Pratt J. Risk aversion in the small and in the large. - Econometrica, 1964, v. 32, p. $122-136$.

7. Рокафеллар P. Выпуклый анализ. М.: Мир, 1973, 469 с.

8. Schweizer M. Variance-optimal hedging in discrete time. - Math. Oper. Res., 1995, v. 20 , № 1, p. 1-32.

9. Summer C. Utility maximization and increasing risk aversion. Ph. D. Thesis. Vienna: Vienna University of Technology, 2002.

Поступила в редакцию

14.VII.2003

Исправленный вариант

1.II. 2005

(c) $2006 \mathrm{r}$.

KAMINSKI M.*

\section{CENTRAL LIMIT THEOREM FOR CERTAIN CLASSES OF DEPENDENT RANDOM VARIABLES ${ }^{1)}$}

\begin{abstract}
Наш главный интерес в этой статье - центральная предельная теорема для зависимых классов случайных величин. Мы вычисляем точную разность между характеристической функцией суммы зависимых случайных величин и характеристической функцией суммы независимых случайных величин с теми же самыми распределениями. Полученная разность служит для определения класса зависимых случайных величин, для которых имеет место обычная сходимость по распределению к нормально распределенной случайной величине. Структура зависимости в том виде, как она определена в нашем классе случайных величин, отвечает определенным физическим явлениям.
\end{abstract}

Ключевые слова и фразы: центральная предельная теорема, зависимые случайные величины.

1. Introduction. During the past century the central limit theorem, CLT, for dependent random variables was one of the most active areas of research. Since Bernstein's paper (1926), many authors have occupied themselves with the problem of extending the central limit theorem for classes of dependent random variables, see for example, [1], [3], or [4]. Various conditions of dependence were derived from the estimation of the difference between characteristic function of averages of dependent and independent random variables. These conditions had some appealing physical interpretations, most often concerned with the passing of time. Dependence structures were defined with the idea that events far separated in time should be stochastically less dependent than close events.

* Department of Mathematics, Oakton Community College, 1600 E. Golf Road, Des Plaines, IL 60016, USA; e-mail: markkaminski2001@yahoo.com 
As it was done before, in this paper we also consider the difference between characteristic function of sums of dependent and independent random variables, but instead of estimation of this diffrence, we find the exact value. We first find the difference between positive dependent and independent random variables. This exact difference between characteristic function of sums of positive dependent and independent random variables is used to estimate the difference of characteristic functions between averages of arbitrary real-valued random variables.

In order to understand how our dependence conditions differ from those defined in preceding works, as an example, let us consider a particular case of random variables. Let $\left\{X_{i}: \Omega \rightarrow[0,1] ; 1 \leqslant i\right\}$ be a sequence of identically distributed random variables such that they satisfy the following dependence condition (which will be proved to be sufficient to satisfy the conclusion of CLT):

$$
\int_{[0,1]^{j}}\left|\mathbf{P}\left(\bigcap_{i=1}^{j}\left\{X_{v_{i}} \leqslant x_{v_{i}}\right\}\right)-\prod_{1=1}^{j} \mathbf{P}\left\{X_{v_{i}} \leqslant x_{v_{i}}\right\}\right| d x_{v_{1}} \cdots d x_{v_{j}} \leqslant\left(1-k^{-\delta / 2}\right)^{k-k^{\delta / 2}-j}
$$

for some $\delta, 0<\delta<1$, and any choice of indices $v_{1}, \ldots, v_{j}$, such that $k^{\delta / 2}<v_{1}<v_{2}<$ $\cdots<v_{j} \leqslant k$. Let us comment the left-hand side of this inequality. Notice that the imposed condition is only on the tail $X_{\left\lfloor k^{\delta / 2}\right\rfloor}, X_{\left\lfloor k^{\delta / 2}\right\rfloor+1}, \ldots, X_{k}$. It is easy to see that the integrand expresses the degree of dependence among $X_{v_{1}}, \ldots, X_{v_{j}}$. Because of the presence of an integral, only the degree of dependence on an «average» matters. This contrasts with conditions of dependence on «event to event» basis, as defined in previous literature. Now, consider the right-hand side of this inequality. Fix $k$ and let $j$ be relatively small, compared to $k$, then the right-hand side of (1) is close to zero. On the other hand, if we set $j$ be large enough, so that it is close to $k-k^{\delta / 2}$, then the expression on the right-hand side of (1) is close to 1 . Hence we allow a stronger dependence within a larger class of random variables and demand more independence within a smaller class. The possibility of allowing the left-hand side of (1) to be close to 1 for large $j$ is the most attractive feature of our class of dependent random variables. Because of this feature, our class can be used to describe systems which are globally determined but locally random (in the sense of unpredictability). In this context our generalization is natural.

2. Results. To simplify our formulas we understand the expression $\left(\prod_{i=1}^{k} a_{i}\right) /$ $\left(a_{v_{1}} \cdots a_{v_{j}}\right), 1 \leqslant v_{1}<\cdots<v_{j} \leqslant k$, as the product of all $a_{i}$ 's except $a_{v_{1}}, \ldots, a_{v_{j}}$, thus this expression makes sense even if one of the terms in the denominator is equal to zero. We start with a lemma which is an elementary computation.

Lemma 1. Let $X$ be a random variable satisfying $0 \leqslant X \leqslant M, M>0$. Let $g:[0, M] \rightarrow C$ be an absolutely continuous function such that $g^{\prime}(x)$ is integrable. Then

$$
\mathbf{E} g(X)=-\int_{0}^{M} g^{\prime}(x) \mathbf{P}\{X \leqslant x\} d x+g(M) .
$$

Extending computations of Lemma 1 to multidimensional cases and computing differences gives us the following lemma.

Lemma 2. Let $X_{1}, X_{2}, \ldots, X_{k}$ be random variables satisfying $0 \leqslant X_{i} \leqslant M, 1 \leqslant i \leqslant k$. Let $g_{1}, \ldots, g_{k}:[0, M] \rightarrow C$ be absolutely continuous integrable functions. Then we have the identity

$$
\begin{aligned}
\mathbf{E}[ & \left.\prod_{i=1}^{k} g_{i}\left(X_{i}\right)\right]-\prod_{i=1}^{k} \mathbf{E} g_{i}\left(X_{i}\right)=\sum_{i=2}^{k} \sum_{1 \leqslant v_{1}<\cdots<v_{j} \leqslant k}(-1)^{j} \frac{\prod_{i=1}^{k} g_{i}(M)}{g_{v_{1}}(M) \cdots g_{v_{j}}(M)} \\
& \times \int_{0}^{M} \cdots \int_{0}^{M} \prod_{i=1}^{j} g_{v_{i}}^{\prime}\left(x_{v_{i}}\right)\left(\mathbf{P}\left(\bigcap_{i=1}^{j}\left\{X_{v_{i}} \leqslant x_{v_{i}}\right\}\right)-\prod_{i=1}^{j} \mathbf{P}\left\{X_{v_{i}} \leqslant x_{v_{i}}\right\}\right) d x_{v_{1}} \cdots d x_{v_{j}} .
\end{aligned}
$$

The identity of Lemma 2 will serve us to compute the difference between characteristic functions of sums of dependent and independent random variables.

C o n d i t i o n 1 . Let $\left\{X_{k, i}: 1 \leqslant i \leqslant r_{k}\right\}$ be a triangular array of random variables, and let $\left\{n_{k}: k \geqslant 1\right\}$ be an increasing sequence of natural numbers and $\left\{\delta_{k}: k \geqslant 1\right\}$ a sequence of increasing positive numbers converging to 1 . Assume that $r_{k}-n_{k} \rightarrow \infty$ as 
$k \rightarrow \infty$ and assume that for sufficiently large $k$, for any choice of indices $v_{1}, \ldots, v_{j}$ such that $n_{k}<v_{1}<\cdots<v_{j} \leqslant r_{k}$, we have the inequality

$\sup \left\{\left|\mathbf{P}\left(\bigcap_{i=1}^{j}\left\{X_{k, v_{i}} \leqslant x_{v_{i}}\right\}\right)-\prod_{i=1}^{j} \mathbf{P}\left\{X_{k, v_{i}} \leqslant x_{v_{i}}\right\}\right|:\left(x_{v_{1}}, \ldots, x_{v_{j}}\right) \in \mathbf{R}^{j}\right\} \leqslant \delta_{k}^{r_{k}-n_{k}-j}$.

C o n d it i o n 2. Let $\left\{X_{k, i}: 1 \leqslant i \leqslant r_{k}\right\},\left\{n_{k}: k \geqslant 1\right\}$, and $\left\{\delta_{k}: k \geqslant 1\right\}$ be as in Condition 1. Assume that for any choice of indices $v_{1}, \ldots, v_{j}$ such that $n_{k}<v_{1}<\cdots<$ $v_{j} \leqslant r_{k}$, we have the inequality

$$
\int_{\mathbf{R}^{j}}\left|\mathbf{P}\left(\bigcap_{i=1}^{j}\left\{X_{k, v_{i}} \leqslant x_{v_{i}}\right\}\right)-\prod_{i=1}^{j} \mathbf{P}\left\{X_{k, v_{i}} \leqslant x_{v_{i}}\right\}\right| d x_{v_{1}} \cdots d x_{v_{j}} \leqslant \delta_{k}^{r_{k}-n_{k}-j} .
$$

It is a trivial observation to notice that Conditions 1 and 2 generalize the independence condition. In our introduction we have already commented on the «meaning» of Condition 2 , in the case of identically distributed random variables, valued in $[0,1]$. Here we do not assume our random variables to be identically distributed, and we allow the possibility that they are boundless. Nevertheless the same comments can be said also in this new situation. Condition 1 differs only from Condition 2 by replacement of an integral by «sup», this change put us into «event to event» basis type of condition.

Proposition 1. Suppose $\left\{X_{k, i}: 1 \leqslant i \leqslant r_{k}\right\}$ is a triangular array of random variables satisfying the Lindeberg condition. Then there exists a sequence of reals $\left\{\varepsilon_{k}: k \geqslant 1\right\}$ such that

$$
\begin{aligned}
\varepsilon_{k} \rightarrow 0 \quad \text { and } \quad \varepsilon_{k} s_{k} \rightarrow+\infty & \text { as } \quad k \rightarrow+\infty, \\
\frac{1}{s_{k}} \sum_{j=1}^{r_{k}} \int_{\left\{\left|X_{k, j}\right|>\varepsilon_{k} s_{k}\right\}}\left|X_{k, j}\right| d \mathbf{P} \rightarrow 0 & \text { as } \quad k \rightarrow+\infty, \\
\left(\frac{1}{s_{k}}\right)^{2} \sum_{j=1}^{r_{k}} \int_{\left\{\left|X_{k, j}\right|>\varepsilon_{k} s_{k}\right\}} X_{k, j}^{2} d \mathbf{P} \rightarrow 0 & \text { as } \quad k \rightarrow+\infty .
\end{aligned}
$$

The existence of such $\left\{\varepsilon_{k}: k \geqslant 1\right\}$ can easily be shown from the Lindeberg condition.

Part 1. General approach. In our first central limit theorem we use Condition 1 with certain restrictions imposed on sequences $\left\{n_{k}: k \geqslant 1\right\}$ and $\left\{\delta_{k}: k \geqslant 1\right\}$. These restrictions define a class of random variables for which our theorem holds. fying:

Theorem 1. Let $\left\{X_{k, i}: 1 \leqslant i \leqslant r_{k}\right\}$ be a triangular array of random variables satis-

(a) Lindeberg condition,

(b) Condition 1 with

$$
n_{k} \leqslant\left[\varepsilon^{-1} \ln \left(1+\varepsilon_{k}^{-1}\right)\right]^{-1},
$$

where $\left\{\varepsilon_{k}: k \geqslant 1\right\}$ is the sequence of Proposition 1 , and

Then we have

$$
\delta_{k}=1-\frac{1}{n_{k^{\prime}}}-\frac{\ln \left(r_{k}-n_{k}\right)}{r_{k}-n_{k}} .
$$

$$
\frac{1}{s_{k}} \sum_{j=1}^{r_{k}}\left(X_{k, j}-\mathbf{E} X_{k, j}\right) \stackrel{D}{\longrightarrow} N(0,1) \quad \text { as } k \rightarrow+\infty .
$$

$\mathrm{P}$ r o o f. Without any loss of generality we can assume that $X_{k, i}$ are centered at 0 , i.e., $\mathbf{E} X_{k, i}=0$. Define the array $\left\{Y_{k, j}: 1 \leqslant j \leqslant r_{k}-n_{k}\right\}$ of random variables as follows: $Y_{k, j}=X_{k, n_{k}+j} I_{\left\{\left|X_{k, n_{k}+j}\right| \leqslant \varepsilon_{k} s_{k}\right\}}+\varepsilon_{k} s_{k}-\varepsilon_{k} s_{k} I_{\left\{X_{k, n_{k}+j} \leqslant-\varepsilon_{k} s_{k}\right\}}+\varepsilon_{k} s_{k} I_{\left\{X_{k, n_{k}+j}>\varepsilon_{k} s_{k}\right\}}$.

We have that $Y_{k, j}$ are positive and bounded by $2 \varepsilon_{k} s_{k}$. Also

$$
\left\{Y_{k, j} \leqslant x\right\}=\left\{X_{k, n_{k}+j} \leqslant-\varepsilon_{k} s_{k}+x\right\}
$$


for all $x$ such that $0 \leqslant x \leqslant 2 \varepsilon_{k} s_{k}$, therefore the inequality of Condition 1 implies that, for all sufficiently large $k$,

$$
\begin{aligned}
& \sup \left\{\left|\mathbf{P}\left(\bigcap_{i=1}^{j}\left\{Y_{k, v_{i}} \leqslant x_{v_{i}}\right\}\right)-\prod_{i=1}^{j} \mathbf{P}\left\{Y_{k, v_{i}} \leqslant x_{v_{i}}\right\}\right|:\left(x_{v_{1}}, \ldots, x_{v_{j}}\right) \in\left[0,2 \varepsilon_{k} s_{k}\right]\right\} \\
& \leqslant \delta_{k}^{r_{k}-n_{k}-j} .
\end{aligned}
$$

To simplify our formulas, we define $r_{k}^{\prime}$ to represent the difference $r_{k}-n_{k}$. We also define the following sequence of positive reals $\left\{c_{k}: k \geqslant 1\right\}$ :

$$
c_{k}^{2}=\sum_{j=1}^{r_{k}^{\prime}} \mathrm{D} Y_{k, j}
$$

We can show that for sufficiently large $k$, the ratio $\left(c_{k} / s_{k}\right)^{2}$ is arbitrarily close to 1 . To verify the Lindeberg condition for $Y_{k, j}$ it is enough to notice that for sufficiently large $k$

$$
\left\{\left|Y_{k, j}-\mathbf{E} Y_{k, j}\right| \geqslant \varepsilon c_{k}\right\}=\varnothing
$$

Our next step is the main part of our proof. We compute the difference between characteristic functions of sums of independent and dependent random variables. By elementary computations, taking $g_{i}(\cdot)=\exp \left(i t\left(\cdot / c_{k}\right)\right), M=2 \varepsilon_{k} c_{k}$, and by Lemma 2, we get

$$
\begin{aligned}
\mid \mathbf{E} & {\left[\exp \left(i t \sum_{j=1}^{r_{k}^{\prime}} \frac{Y_{k, j}-\mathbf{E} Y_{k, j}}{c_{k}}\right)\right]-\prod_{j=1}^{r_{k}^{\prime}} \mathbf{E}\left[\exp \left(i t \frac{Y_{k, j}-\mathbf{E} Y_{k, j}}{c_{k}}\right)\right] \mid } \\
= & \mid \sum_{j=2}^{k} \sum_{1 \leqslant v_{1}<\cdots<v_{j} \leqslant r_{k}^{\prime}}(-1)^{j} \exp \left[2 \varepsilon_{k} s_{k} i t\left(r_{k}^{\prime}-j\right)\right] \\
& \times \int_{\left[0,2 \varepsilon_{k} s_{k}\right]^{j}}\left(\frac{i t}{c_{k}}\right)^{j} \exp \left[\frac{i t}{c_{k}}\left(x_{v_{1}}+\cdots+x_{v_{j}}\right)\right] \\
& \times\left[\mathbf{P}\left(\bigcap_{i=1}^{j}\left\{Y_{k, v_{i}} \leqslant x_{v_{i}}\right\}\right)-\prod_{i=1}^{j} \mathbf{P}\left\{Y_{k, v_{i}} \leqslant x_{v_{i}}\right\}\right] d x_{v_{1}} \cdots d x_{v_{j}} \mid
\end{aligned}
$$

and from Condition 1 we have

$$
\begin{aligned}
& \int_{\left[0,2 \varepsilon_{k} s_{k}\right]^{j}}\left(\frac{i t}{c_{k}}\right)^{j} \exp \left[\frac{i t}{c_{k}}\left(x_{v_{1}}+\cdots+x_{v_{j}}\right)\right] \\
& \quad \times\left|\mathbf{P}\left(\bigcap_{i=1}^{j}\left\{Y_{k, v_{i}} \leqslant x_{v_{i}}\right\}\right)-\prod_{i=1}^{j} \mathbf{P}\left\{Y_{k, v_{i}} \leqslant x_{v_{i}}\right\}\right| d x_{v_{1}} \cdots d x_{v_{j}} \leqslant \delta_{k}^{r_{k}^{\prime}-j}\left|\frac{2 \varepsilon_{k} s_{k} t}{c_{k}}\right|^{j} .
\end{aligned}
$$

By condition (10) of the theorem,

$$
\begin{aligned}
\mid \mathbf{E} & {\left[\exp \left(i t \sum_{j=1}^{r_{k}^{\prime}} \frac{Y_{k, j}-\mathbf{E} Y_{k, j}}{c_{k}}\right)\right]-\prod_{j=1}^{r_{k}^{\prime}} \mathbf{E}\left[\exp \left(\frac{i t\left(Y_{k, j}-\mathbf{E} Y_{k, j}\right)}{c_{k}}\right)\right] \mid } \\
& \leqslant \sum_{j=2}^{r_{k}^{\prime}}\left(\begin{array}{c}
r_{k}^{\prime} \\
j
\end{array}\right)\left|1-\varepsilon_{k} \ln \left(1+\varepsilon_{k}^{-1}\right)-\frac{\ln r_{k}^{\prime}}{r_{k}^{\prime}}\right|^{r_{k}^{\prime}-j}\left|\frac{2 \varepsilon_{k} s_{k} t}{c_{k}}\right|^{j} \\
& <\left(1-\varepsilon_{k} \ln \left(1+\varepsilon_{k}^{-1}\right)-\frac{\ln r_{k}^{\prime}}{r_{k}^{\prime}}+\left|\frac{2 \varepsilon_{k} s_{k} t}{c_{k}}\right|\right)^{r_{k}^{\prime}} .
\end{aligned}
$$

Since for sufficiently large $k$ we have $-\varepsilon_{k} \ln \left(1+\varepsilon_{k}^{-1}\right)+\left|2 \varepsilon_{k} s_{k} t / c_{k}\right|<0$, the last expression can be estimated from above by $\left(1-\left(\ln r_{k}^{\prime}\right) / r_{k}^{\prime}\right)^{r_{k}^{\prime}}$ which converges to 0 as $k \rightarrow+\infty$. Hence we have obtained that expression (16) converges to 0 . Next, we define a triangular array $\left\{W_{k, j}: 1 \leqslant j \leqslant r_{k}^{\prime}\right\}$ of random variables such that $W_{k, j}$ are independent in each row, and equidistributed with $Y_{k, j}$. Since the Lindeberg condition was satisfied by $Y_{k, j}$, 
therefore it also holds for $W_{k, j}$. Therefore, CLT is true for $W_{k, j}$, since the expression (17) converges to 0 , we can show that CLT is also true for $Y_{k, j}$, which means that

$$
\frac{1}{c_{k}} \sum_{j=1}^{r_{k}^{\prime}}\left(Y_{k, j}-\mathbf{E} Y_{k, j}\right) \stackrel{D}{\longrightarrow} N(0,1) \quad \text { as } k \rightarrow+\infty \text {. }
$$

Using the definition of $Y_{k, j}$ and taking into account that $s_{k}^{2} / c_{k}^{2} \rightarrow 1$, we can show that (17) implies

$$
\frac{1}{s_{k}} \sum_{j=n_{k}+1}^{r_{k}} X_{k, j} \stackrel{D}{\longrightarrow} N(0,1) \quad \text { as } \quad k \rightarrow+\infty .
$$

Also, we can show from (9) that

$$
\frac{1}{s_{k}} \sum_{j=1}^{n_{k}} X_{k, j} \stackrel{L_{1}}{\longrightarrow} 0 \quad \text { as } \quad k \rightarrow+\infty .
$$

Relations (19) and (20) imply that

$$
\frac{1}{s_{k}} \sum_{j=1}^{r_{k}} X_{k, j} \rightarrow N(0,1) \quad \text { as } \quad k \rightarrow+\infty
$$

which ends the proof.

In our next theorem we use Condition 2. fying

Theorem 2. Let $\left\{X_{k, i}: 1 \leqslant i \leqslant r_{k}\right\}$ be a triangular array of random variables satis-

(a) the Lindeberg condition,

(b) Condition 2 with

$$
n_{k} \leqslant\left[\varepsilon \ln \left(1+\varepsilon_{k}^{-1}\right)\right]^{-1}
$$

where $\left\{\varepsilon_{k}: k \geqslant 1\right\}$ is a sequence of Proposition 1 , and

Then

$$
\delta_{k}=1-\frac{\ln s_{k}}{s_{k}}-\frac{\ln \left(r_{k}-n_{k}\right)}{r_{k}-n_{k}}
$$

$$
\frac{1}{s_{k}} \sum_{j=1}^{r_{k}}\left(X_{k, j}-\mathbf{E} X_{k, j}\right) \stackrel{D}{\longrightarrow} N(0,1) \quad \text { as } k \rightarrow+\infty .
$$

P r o o f. Our proof follows the same way as the proof of Theorem 1 except that now, in order to estimate the difference between characteristic functions of the sums of dependent and independent random variables, we will use Condition 2 instead of Condition 1. We have

$$
\begin{aligned}
& \left|\mathbf{E}\left[\exp \left(i t \sum_{j=1}^{r_{k}^{\prime}} \frac{Y_{k, j}}{c_{k}}\right)\right]-\prod_{j=1}^{r_{k}^{\prime}} \mathbf{E}\left[\exp \left(\frac{i t Y_{k, j}}{c_{k}}\right)\right]\right| \\
& \leqslant \mid \sum_{j=2}^{k} \sum_{1 \leqslant v_{1}<\cdots<v_{j} \leqslant r_{k}^{\prime}} \int_{\left[0,2 \varepsilon_{k} s_{k}\right]^{j}}\left(\frac{i t}{c_{k}}\right)^{j} \exp \left[\frac{i t}{c_{k}}\left(x_{v_{1}}+\cdots+x_{v_{j}}\right)\right] \\
& \quad \times\left[\mathbf{P}\left(\bigcap_{i=1}^{j}\left\{Y_{k, v_{i}} \leqslant x_{v_{i}}\right\}\right)-\prod_{i=1}^{j} \mathbf{P}\left\{Y_{k, v_{i}} \leqslant x_{v_{i}}\right\}\right] d x_{v_{1}} \cdots d x_{v_{j}} \mid \\
& \leqslant \sum_{j=2}^{r_{k}^{\prime}}\left(\begin{array}{c}
r_{k}^{\prime} \\
j
\end{array}\right)\left|\frac{t}{c_{k}}\right|^{j}\left[1-\frac{\ln s_{k}}{s_{k}}-\frac{\ln r_{k}^{\prime}}{r_{k}^{\prime}}\right]^{r_{k}^{\prime}-j} \leqslant\left[1-\frac{\ln s_{k}}{s_{k}}-\frac{\ln r_{k}^{\prime}}{r_{k}^{\prime}}+\left|\frac{t}{c_{k}}\right|\right]^{r_{k}^{\prime}} .
\end{aligned}
$$

For sufficiently large $k$, we have $-\left(\ln s_{k}\right) / s_{k}+\left|t / c_{k}\right|<0$, therefore

$$
\left|\mathbf{E}\left[\exp \left(i t \sum_{j=1}^{r_{k}^{\prime}} \frac{Y_{k, j}}{c_{k}}\right)\right]-\prod_{j=1}^{r_{k}^{\prime}} \mathbf{E}\left[\exp \left(\frac{i t Y_{k, j}}{c_{k}}\right)\right]\right|<\left[1-\frac{\ln r_{k}^{\prime}}{r_{k}^{\prime}}\right]^{r_{k}^{\prime}} \rightarrow 0 \quad \text { as } \quad k \rightarrow+\infty \text {. }
$$

The remaining part of the proof follows as in the proof of Theorem 1. 
Part 2. Identically distributed random variables. In part 2 we consider sequences of identically distributed random variables. From Proposition 1 we know that there exists a sequence $\left\{\varepsilon_{k}: k \geqslant 1\right\}$ of positive reals such that (6), (7), and (8) hold. In the case of $\left\{X_{i}: i \geqslant 1\right\}$ being identically distributed random variables, we can slightly weaken conditions imposed on $X_{i}$ in the assumptions of previous theorems. This extra condition will allow us to state our theorems in the clearer and simpler form. The following is only a modification of Theorem 1 to the case of identically distributed random variables.

Theorem 3. Let $\left\{X_{i}: i \geqslant 1\right\}$ be a sequence of identically distributed random variables such that $\mathbf{E}\left|X_{1}\right|^{2+\varepsilon}<+\infty$ for some $\varepsilon>0$. Let $\varepsilon_{1}$ be a real number such that $\varepsilon_{1}<$ $\frac{1}{2}(\varepsilon /(1+\varepsilon))$. Suppose that for sufficiently large $k$, the inequality

$$
\begin{aligned}
& \sup \left\{\left|\mathbf{P}\left(\bigcap_{i=1}^{j}\left\{X_{v_{i}} \leqslant x_{v_{i}}\right\}\right)-\prod_{1=1}^{j} \mathbf{P}\left\{Y_{v_{i}} \leqslant x_{v_{i}}\right\}\right|:\left(x_{v_{1}}, \ldots, x_{v_{j}}\right) \in \mathbf{R}^{j}\right\} \\
& \leqslant\left(1-k^{-\varepsilon_{1}}\right)^{k-k^{\varepsilon_{1}}-j}
\end{aligned}
$$

holds, where $v_{1}, \ldots, v_{j}$ is any choice of indices such that $k^{\varepsilon_{1}}<v_{1}<\cdots<v_{j} \leqslant k$. Then

$$
\frac{1}{\sigma \sqrt{k}} \sum_{i=1}^{k}\left(X_{i}-\mathbf{E} X_{i}\right) \stackrel{D}{\longrightarrow} N(0,1) \quad \text { as } k \rightarrow+\infty \text {. }
$$

$\mathrm{P}$ r o o f. Assume that $\mathbf{E} X_{i}=0$. Let $\varepsilon_{1}<\frac{1}{2} \varepsilon /(1+\varepsilon)$ be given. Choose $\varepsilon_{2}$ so that $\varepsilon_{1}<\varepsilon_{2}<\frac{1}{2} \varepsilon /(1+\varepsilon)$. Define the sequence $\left\{\varepsilon_{k}: k \geqslant 3\right\}$ by $\varepsilon_{k}=k^{-\varepsilon_{2}}$. We can easily verify that (6) of Proposition 1 holds. Moreover, we have

$$
\begin{aligned}
\frac{1}{s_{k}} \sum_{i=1}^{k} \int_{\left\{\left|X_{i}\right|>\varepsilon_{k} s_{k}\right\}}\left|X_{i}\right| d \mathbf{P} & =\frac{1}{\sigma} \frac{k}{\sqrt{k}} \int_{\left\{\left|X_{1}\right|>\sigma k^{\left.1 / 2-\varepsilon_{2}\right\}}\right.}\left|X_{1}\right| d \mathbf{P} \\
& \leqslant \frac{\sqrt{k}}{\sigma}\left(\frac{1}{\sigma k^{1 / 2-\varepsilon_{2}}}\right)^{1+\varepsilon} \int_{\left\{\left|X_{1}\right|>\sigma k^{\left.1 / 2-\varepsilon_{2}\right\}}\right.}\left|X_{1}\right|^{2+\varepsilon} d \mathbf{P} .
\end{aligned}
$$

Since $\varepsilon_{2}<\frac{1}{2} \varepsilon /(1+\varepsilon)$, the above expression converges to 0 as $k \rightarrow+\infty$. Hence we have shown (7) of Proposition 1 . Now to verify (8), note that

$$
\begin{aligned}
& \left(\frac{1}{s_{k}}\right)^{2} \sum_{i=1}^{k} \int_{\left\{\left|X_{1}\right|>\sigma k^{1 / 2-\varepsilon_{2}}\right\}}\left|X_{1}\right|^{2} d \mathbf{P} \\
& =\left(\frac{1}{\sigma}\right)^{2} \int_{\left\{\left|X_{1}\right|>\sigma k^{1 / 2-\varepsilon_{2}}\right\}}\left|X_{1}\right|^{2} d \mathbf{P} \rightarrow 0 \text { as } k \rightarrow+\infty .
\end{aligned}
$$

For sufficiently large $k$, we have

$$
k^{\varepsilon_{1}}<\frac{k^{\varepsilon_{2}}}{\ln \left(1+k^{\varepsilon_{2}}\right)} .
$$

Therefore, if we take $n_{k}=\left\lfloor k^{\varepsilon_{1}}\right\rfloor$, where $\left\lfloor k^{\varepsilon_{1}}\right\rfloor$ denotes the integer part of $k^{\varepsilon_{1}}$, then condition (9) of Theorem 1 is satisfied. Following the path of the proof of Theorem 1, we define

$$
Y_{j}=X_{n_{k}+j} I_{\left\{\left|X_{n_{k}+j}\right| \leqslant \varepsilon_{k} s_{k}\right\}}+\varepsilon_{k} s_{k}-\varepsilon_{k} s_{k} I_{\left\{X_{n_{k}+j}<-\varepsilon_{k} s_{k}\right\}}+\varepsilon_{k} s_{k} I_{\left\{X_{n_{k}+j}>\varepsilon_{k} s_{k}\right\}}
$$

and let $c_{k}^{2}=\sum_{j=1}^{k-\left\lfloor k^{\varepsilon_{1}}\right\rfloor} \mathbf{D} Y_{j}$. In this case,

$$
\begin{aligned}
\mid \mathbf{E} & {\left[\exp \left[\frac{i t}{c_{k}} \sum_{j=1}^{k-\left\lfloor k^{\varepsilon_{1}}\right\rfloor}\left(Y_{j}-\mathbf{E} Y_{j}\right)\right]\right]-\prod_{j=1}^{k-\left\lfloor k^{\left.\varepsilon_{1}\right\rfloor}\right.} \mathbf{E}\left[\exp \left[\frac{i t}{c_{k}}\left(Y_{j}-\mathbf{E} Y_{j}\right)\right]\right] \mid } \\
\leqslant & \mid \sum_{j=2}^{k} \sum_{1 \leqslant v_{1}<\cdots<v_{j} \leqslant k-\left\lfloor k^{\varepsilon_{1}}\right\rfloor} \int_{\left[0,2 \varepsilon_{k} s_{k}\right]^{j}}\left(\frac{i t}{c_{k}}\right)^{j} \exp \left[\frac{i t}{c_{k}}\left(x_{v_{1}}+\cdots+x_{v_{j}}\right)\right] \\
& \times\left[\mathbf{P}\left(\bigcap_{i=1}^{j}\left\{Y_{k, v_{i}} \leqslant x_{v_{i}}\right\}\right)-\prod_{i=1}^{j} \mathbf{P}\left\{Y_{k, v_{i}} \leqslant x_{v_{i}}\right\}\right] d x_{v_{1}} \cdots d x_{v_{j}} \mid
\end{aligned}
$$




$$
\begin{aligned}
& \leqslant c \sum_{j=2}^{k-\left\lfloor k^{\left.\varepsilon_{1}\right\rfloor}\right.}\left(\begin{array}{c}
k-\left\lfloor k^{\left.\varepsilon_{1}\right\rfloor}\right. \\
j
\end{array}\right)\left(1-k^{-\varepsilon_{1}}\right)^{k-\left\lfloor k^{\varepsilon_{1}}\right\rfloor-j}\left|2\left\lfloor k^{\varepsilon_{2}}\right\rfloor t\left(\frac{s_{k}}{c_{k}}\right)\right|^{j} \\
& <\left[1-k^{-\varepsilon_{1}}+2 k^{-\varepsilon_{2}}|t| \frac{s_{k}}{c_{k}}\right]^{k-\left\lfloor k^{\varepsilon_{1}}\right\rfloor},
\end{aligned}
$$

where $s_{k}=\sum_{j=1}^{k} \mathbf{D} X_{j}$ and $c$ is a positive constant. Since $\varepsilon_{2}>\varepsilon_{1}$ and $s_{k} / c_{k} \rightarrow 1$ as $k \rightarrow+\infty$, the last expression converges to 0 as $k \rightarrow+\infty$. The rest of the proof follows the same way as the proof of Theorem 1.

Corollary 1. Suppose $\left\{X_{j}: j \geqslant 1\right\}$ is a sequence of identically distributed random variables such that $\mathbf{E}\left|X_{1}\right|^{n}<+\infty, n \in \mathbf{N}$. Suppose there exists $\delta, 0<\delta<1$, such that for sufficiently large $k$ the inequality

$$
\begin{aligned}
& \sup \left\{\left|\mathbf{P}\left(\bigcap_{i=1}^{j}\left\{X_{v_{i}} \leqslant x_{v_{i}}\right\}\right)-\prod_{1=1}^{j} \mathbf{P}\left\{Y_{v_{i}} \leqslant x_{v_{i}}\right\}\right|:\left(x_{v_{1}}, \ldots, x_{v_{j}}\right) \in \mathbf{R}^{j}\right\} \\
& \leqslant\left(1-k^{-\delta / 2}\right)^{k-k^{\delta / 2}-j}
\end{aligned}
$$

holds, where $v_{1}, \ldots, v_{j}$ is any choice of indices such that $k^{\delta / 2}<v_{1}<\cdots<v_{j} \leqslant k$. Then

$$
\frac{1}{\sigma \sqrt{k}} \sum_{i=1}^{k}\left(X_{i}-\mathbf{E} X_{i}\right) \stackrel{D}{\longrightarrow} N(0,1) \quad \text { as } k \rightarrow+\infty .
$$

The proof follows directly from Theorem 3 .

In order to verify that our theorems are not vainly true, we present an example of the sequence $\left\{X_{j}: j \geqslant 1\right\}$ of random variables which satisfy conditions of Corollary 1 (one can also verify that they are 2-exchangeable, and therefore satisfy the law of large numbers [5]). Define the joint density function

$$
f_{X_{v_{1}}, \ldots, X_{v_{s}}}\left(x_{v_{1}}, \ldots, x_{v_{s}}\right)=1+\sum_{\substack{j_{1} \neq j_{2} \\ j_{1}, j_{2} \in\left\{v_{1}, \ldots, v_{s}\right\}}}\left(\frac{1}{2}\right)^{j_{1}+j_{2}} \cos \left(2 \pi x_{j_{1}}\right) \cos \left(2 \pi x_{j_{2}}\right)
$$

with $\left\{X_{j}: j \geqslant 1\right\}$ defined this way, one can show that for sufficiently large $k$,

$$
\left|\mathbf{P}\left(\bigcap_{i=1}^{j}\left\{X_{v_{i}} \leqslant x_{v_{i}}\right\}\right)-\prod_{1=1}^{j} \mathbf{P}\left\{Y_{v_{i}} \leqslant x_{v_{i}}\right\}\right| \leqslant\left(\frac{1}{\pi}\right)^{2}\left(\frac{1}{4}\right)^{k^{\delta / 2}} \leqslant\left(1-k^{-\delta / 2}\right)^{k-k^{\delta / 2}-j} \text {. }
$$

Our next theorem is a modification of Theorem 2 to the case of identically distributed random variables.

Theorem 4. Let $\left\{X_{i}: i \geqslant 1\right\}$ be a sequence of identically distributed random variables. Suppose that $\mathbf{E}\left|X_{1}\right|^{2+\varepsilon}<+\infty$ for some $\varepsilon>0$. Let $\varepsilon_{1}$ be a real number such that $0<\varepsilon_{1}<$ $\frac{1}{2}(\varepsilon /(1+\varepsilon))$. If for sufficiently large $k$

$$
\int_{\mathbf{R}^{j}}\left|\mathbf{P}\left(\bigcap_{i=1}^{j}\left\{X_{v_{i}} \leqslant x_{v_{i}}\right\}\right)-\prod_{1=1}^{j} \mathbf{P}\left\{Y_{v_{i}} \leqslant x_{v_{i}}\right\}\right| d x_{v_{1}} \cdots d x_{v_{j}} \leqslant\left(1-k^{-\varepsilon_{1}}\right)^{k-k^{\varepsilon_{1}}-j}
$$

where $v_{1}, \ldots v_{j}$ is any choice of indices such that $k^{\varepsilon_{1}}<v_{1}<\cdots<v_{j} \leqslant k$, then

$$
\frac{1}{\sigma \sqrt{k}} \sum_{i=1}^{k}\left(X_{i}-\mathbf{E} X_{i}\right) \stackrel{D}{\longrightarrow} N(0,1) \quad \text { as } k \rightarrow+\infty
$$

P r o of. We define $Y_{j}, c_{k}$, and $n_{k}$ as in the proof of Theorem 1 . We have

$$
\begin{aligned}
& \left|\mathbf{E}\left[\exp \left(\frac{i t}{c_{k}} \sum_{j=1}^{k-\left\lfloor k^{\varepsilon_{1}}\right\rfloor}\left(Y_{j}-\mathbf{E} Y_{j}\right)\right)\right]-\prod_{j=1}^{k-\left\lfloor k^{\varepsilon_{1}}\right\rfloor} \mathbf{E}\left[\exp \left(\frac{i t}{c_{k}}\left(Y_{j}-\mathbf{E} Y_{j}\right)\right)\right]\right| \\
& \leqslant C \sum_{j=2}^{k-\left\lfloor k^{\varepsilon_{1}}\right\rfloor}\left(\begin{array}{c}
k-\left\lfloor k^{\varepsilon_{1}}\right\rfloor \\
j
\end{array}\right)\left|\frac{t}{c_{k}}\right|^{j}\left(1-k^{-\varepsilon_{1}}\right)^{k-\left\lfloor k^{\varepsilon_{1}}\right\rfloor-j}<C\left[1-k^{-\varepsilon_{1}}+\left|\frac{t}{c_{k}}\right|\right]^{k-\left\lfloor k^{\varepsilon_{1}}\right\rfloor},
\end{aligned}
$$

where $C$ is a positive constant. Since $c_{k} / s_{k} \rightarrow 1$ and $s_{k}=\sigma k^{1 / 2}$, the last expression converges to 0 as $k \rightarrow+\infty$. The rest of the proof is identical to the proof of Theorem 2 . 
Corollary 2. Suppose $\left\{X_{i}: i \geqslant 1\right\}$ is a sequence of identically distributed random variables such that $\mathbf{E}\left|X_{1}\right|<+\infty, n \in \mathbf{N}$. If there exists $\delta, 0<\delta<1$, such that for sufficiently large $k$

$$
\int_{\mathbf{R}^{j}}\left|\mathbf{P}\left(\bigcap_{i=1}^{j}\left\{X_{v_{i}} \leqslant x_{v_{i}}\right\}\right)-\prod_{1=1}^{j} \mathbf{P}\left\{Y_{v_{i}} \leqslant x_{v_{i}}\right\}\right| d x_{v_{1}} \cdots d x_{v_{j}} \leqslant\left(1-k^{-\delta / 2}\right)^{k-k^{\delta / 2}-j},
$$

where $v_{1}, \ldots, v_{j}$ is any choice of indices such that $k^{\delta / 2}<v_{1}<\cdots<v_{j} \leqslant k$, then

$$
\frac{1}{\sigma \sqrt{k}} \sum_{i=1}^{k}\left(X_{i}-\mathbf{E} X_{i}\right) \stackrel{D}{\longrightarrow} N(0,1) \quad \text { as } k \rightarrow+\infty .
$$

The proof follows directly from Theorem 4.

\section{REFERENCES}

1. Bernstein S. Sur l'extension du théorème limite du calcul des probabilités aux sommes de quantités dépendantes. - Math. Ann., 1926, v. 97, pp. 1-59; pyc. перев.: Бернштейн С. Н. Распространение предельной теоремы теории вероятностей на суммы зависимых величин. - Успехи матем. наук, 1944, т. 10, с. 65-114.

2. Billingsley P. Probability and Measure. New York: Wiley, 1986, 622 p.

3. Kuelbs J., Philipp $W$. Almost sure invariance principles for sums of mixing $B$-valued random variables. - Ann. Probab., 1980, v. 8, №6, p. 1003-1036.

4. Rosenblatt $M$. A central limit theorem and a strong mixing condition. - Proc. Natl. Acad. Sci. USA, 1956, v. 42, p. 43-47.

5. Etemadi N., Kaminski $M$. Strong law of large numbers for 2-exchangeable random variables. - Statist. Probab. Lett., 1996, v. 28, № 3, p. 245-250.

Поступила в редакцию

6.XII.2004

(c) $2006 \mathrm{r}$.

KLOTZ L.*

\section{SOME REMARKS ON AN INTERPOLATION PROBLEM OF A. M. YAGLOM}

В статье рассматривается проблема наилучшей интерполяции в смысле среднеквадратической ошибки для непрерывного $q$-мерного слабо стационарного процесса $\mathbf{x}$ на $\mathbf{R}$, если известны $x_{k}, k \in \mathbf{Z}$. Такая проблема виервые изучалась А.М. Ягломом [14] в случае $q=1$. Пусть $\mathscr{J}_{\mathbf{Z}}$ обозначает семейство всех подмножеств множества $\mathbf{R}$, которые получаются сдвигами множества Z. C помощью спектральной меры процесса $\mathbf{x}$ выводятся критерии $\mathscr{J}_{\mathbf{Z}}$-сингулярности и $\mathscr{J}_{\mathbf{Z}}$-регулярности. Аналогичные результаты сформулируются для стационарных случайныг последовательностей на $\mathbf{Z}$.

Ключевые слова и фразы: $q$-мерный слабо стационарный процесс, лучшая интерполяция в смысле среднеквадратической ошибки, $\mathscr{J} \mathbf{z}$-регулярность и $\mathscr{J}$-сингулярность, линейная фильтрация.

* Fakultät für Mathematik und Informatik, Universität Leipzig, Augustusplatz, D-04109 Leipzig; e-mail: klotz@math.uni-leipzig.de 